\title{
Communicative disability and stories: Towards an embodied conception of narratives
}

\author{
Lars-Christer Hydén and Eleonor Antelius
}

\section{Linköping University Post Print}

N.B.: When citing this work, cite the original article.

Original Publication:

Lars-Christer Hydén and Eleonor Antelius, Communicative disability and stories: Towards an embodied conception of narratives, 2011, Health, (15), 6, 588-603.

http://dx.doi.org/10.1177/1363459310364158

Copyright: SAGE Publications (UK and US)

http://www.uk.sagepub.com/

Postprint available at: Linköping University Electronic Press

http://urn.kb.se/resolve?urn=urn:nbn:se:liu:diva-18322 
COMMUNICATIVE DISABILITY AND STORIES: TOWARDS AN EMBODIED CONCEPTION OF NARRATIVES

FINAL VERSION

L. C. Hydén

Eleonor Antelius

Department of Medicine and Health Studies

Linköping University

Sweden

Corresponding author:

Lars-Christer.Hyden@liu.se 


\section{Abstract}

In this article we show that persons with communicative disabilities are often involved in storytelling that does not necessarily conform to the conventional expectations of what constitutes a narrative. By analyzing the relationship between story and storytelling event, and the relationship between what could be called the primary storyteller and the vicarious storyteller, we show that storytellers with communicative disabilities are often quite inventive in finding ways of presenting themselves as competent storytellers even though they may have certain problems vocally animating a coherent, structured story. This leads us to make a necessary redefinition of what a narrative is - that it can be performed as well as it can be told - and that such a redefinition stresses methodological issues. In order to be able to study the life stories of people with communicative disabilities we need to use both narrative and ethnographic research methods.

Keywords: narrative, communicative disability, joint activity 


\section{$\underline{\text { Introduction }}$}

Telling and listening to stories is one of the most powerful instruments we have for sharing experiences and knowledge. Stories are a special way of letting us 'see' and experience the world through the 'eyes' of other persons. The stories are therefore important tools for inviting into and establishing, confirming and negotiating common shared worlds. This is one of the reasons why researchers have been interested in collecting and listening to stories. It is especially true of researchers working in fields where people have experiences and stories that are either not known to other people or not recognized as valid experiences, but are rather regarded in terms of symptoms of a disease. Collecting and analyzing narratives has been thought of as a way to understand these kinds of experiences and life histories. Stories are often thought to give 'the view from within', and to be a way to access subjectivity and experience directly. Recently several researchers have suggested that narrative forms of inquiry can be of interest in the field of disability studies (cf. Smith and Sparkes, 2008; Goodley and Tregaskis, 2006). Collecting and analyzing stories from persons with disabilities is thought of as a way to understand and describe experiences, and above all to contextualize these experiences politically and culturally.

In this article we wish to discuss what we consider an important but somewhat neglected problem in this context: how to think about and analyze stories when the storyteller has impairments that affect his or her ability and possibility to tell stories in interaction with other persons. Not being able to tell stories can make it difficult to engage in social interaction with others, to share experiences and points of view. This can be true of persons suffering from brain injury or a disease like Alzheimer's. We suggest that one important reason why problems may occur - both in everyday interaction and in research settings - has to do with the taken-for-granted and often implicit narrative norms. Stories are generally considered discursive or textual units, characterized by topical and temporal coherence. Stories that don't live up to these norms are generally considered 'failed' stories. As a consequence the storyteller may appear to be less competent and agentive than what is actually the case.

In the following we would like to suggest some ways of thinking about storytelling and narratives told by persons suffering from primarily brain injuries that stress the competence and creativity of the storyteller. First, we argue that the narrative theoretical traditions often take the written story as the paradigmatic example of a narrative, hence leaving much of the storytelling situation and activity outside the analysis. Second, we want to emphasize the fact 
that stories are co-constructed in the storytelling event and that it's necessary to understand stories as jointly constructed. We introduce a distinction between primary and vicarious storytellers. We argue that storytellers who experience troubles in telling stories are often quite inventive in organizing the interaction in order to appear as the primary storytellers. Finally we discuss the consequences of approach on theoretical and methodological issues regarding narrative studies and communicative disabilities.

\section{$\underline{\text { Stories and norms }}$}

In research about illness and disability it is not uncommon that many aspects of the embodied and performed storytelling are left out of the analysis. In a comment on the state of the art in narrative studies, British sociologist Brett Smith writes:

narrative researchers should not simply be content with theories and conceptual musing on and about the body. We also might turn our attention to generating stories from and with actual lived and living human bodies (....). Bodies are partly connected and 'known' through narrative - the stories they tell. Indeed, we tell stories about, in, out of, and through our bodies. Likewise, as a resource, stories from outside our bodies endow us with a sense of interior, subjective reality and are integral to efforts to communicate our feelings to others (...) This is a call, in effect, for an embodied rather than a disembodied narrative inquiry. (Smith, 2007: 395)

Although Brett Smith's observation concerns narrative research in general his comments are particularly relevant for the study of narratives in the field of illness and disability. What he points out is that the body in narrative research often is just the represented body - not the actual physical bodies that are present in the storytelling event and that are telling and listening to the story. Stories are actually embodied in the gestures, the linguistic, paralinguistic, non-verbal and other physical artifacts that are used as resources in telling and listening to a story. As Brett Smith points out it is these storytelling bodies that often are left out of the narrative analysis - bodies that also carry the experiences that are the topic of the stories. Not including the actual bodies in the analysis becomes especially problematic in understanding persons that have bodies afflicted with illness or dysfunction. The reason is that dysfunctional bodies often intervene, more or less, in the stories these persons tell or try to tell, affecting both the structure and the functions of the story. 
One reason that many researchers working with disability studies or illness tend to leave the body outside narrative analysis probably has to do with some of the theoretical heritage of narrative theory. Historically one of the fundamental theoretical lineages of narrative theory goes back to literary theory and has to do with the question of how to define what a narrative is. In literary theory the basic paradigmatic example of a narrative is the written story, for instance the novel or written versions of tales. The written story is generally a well-defined entity, with a clear beginning, middle and end. The written story in many ways also invites a reading and interpretation that excludes or at least makes various contexts less important, whether it is the specific context of the reading situation or the more general cultural and historical context. This conception of narrative is probably best represented in the narratological tradition, and has been widely criticized in literary theory (for a recent account, see Walsh, 2007). Nevertheless the narratological conception of narrative has been widely and maybe unintentionally - used by social science researchers, especially in fields like life story research and narrative identity studies in areas like health and medicine (see Hydén and Brockmeier, 2008).

Due to this literary and narratological past many social scientific researchers have tended to conceive and analyze stories told in interviews or identified in observation data as if they dealt with a written story. Hence, the focus is often on the discursive organization of the narrative in terms of coherence, plot and so on. Generally it also implies that the meaning of the narrative can be found in the narrative text as such. And finally, it implies that the narrative primarily is a representation of events in the past. This approach implies that narratives told in interviews or in some other kind of interaction is analyzed in relation to norms for written text production. That is, they are analyzed as if they are instances of written autobiographical texts. One problem with this approach is that the norms for written stories are in many ways different from those of spoken language, as has been pointed out by several researchers (see Linell, 2005, for a review). Above all, the written narrative allows a more elaborate and formal style and use of imagery, and a refined chronology of events as compared to stories told in conversations. These norms and forms for written narratives are rarely used in the telling of oral, conversational narratives, where those aspects having to do with the necessity and importance of engaging the audience through the whole storytelling event and delivering a point are much more important (Bauman, 1987). 
A second problem has to do with the fact that written narratives are generally composed in order to be read and consumed by anonymous readers in quite different settings and points in time, something that to a certain degree makes written stories de-contextualized. Whereas oral narratives are heavily dependent on the specific social situation, audience, physical setting, gestures, prosody, etcetera; that is, aspects related to the performance of the narrative. In producing a text, at least some of these contextual resources have to be transformed into textual elements (commas, dots, question marks, etc).

A third problem has to do with the transformation of speech into text. The norms for written stories often guide the transcription of interview or observational material into written text used for analysis of stories. If narratives told in interviews are transcribed without notation for hesitations, pauses, repair, listener support, para-linguistic features, non-verbal aspects and so on, it means that all interactional features of the performance of the narrative and its embodiment are left out. Consequentially everything 'outside' the narrative text is left out of the analysis, which makes it difficult to analyze the telling of stories as social action.

In many cases a focus on the narrative text can of course be a feasible strategy - especially if researchers primarily use narratives as a way of accessing representations of events in the past. But a focus on the narrative as text becomes problematic if researchers instead are interested in the functions of the narrative and the storytelling, that is, what is accomplished through the telling of a story. In studies using an ethnographic or micro-ethnographic approach it is often found that storytelling occurs at certain moments in the social interaction, joining tellers and listeners in concerted action, sharing experiences or memories. Storytelling can then be seen as part of a family's or a group's social life, establishing, re-establishing and negotiating, relations, membership and connections (Langellier and Peterson, 2004; also see Heath, 1983 for social variation in this kind of oral stories).

The focus on storytelling in various social contexts has led many researchers to focus on both the performance of the story and its performative aspects as well as embodiment. That is, on both the way the story is told and performed in interaction jointly with the listeners, and what is done or accomplished through the telling of the story (Bauman and Briggs, 1990; Hydén and Brockmeier, 2008; Langellier, 2001; Peterson and Langellier, 2006).

To many researchers a performative and embodied approach also makes it possible to regard 
language not just as a vehicle used to communicate a story. Instead of a focus 'on processes within the individual or on structure within the talk of a single speaker or narrator' it instead becomes important to regard 'how language is organized as a public sign system' (Goodwin, 2004: 154). As a consequence the focus is much more on how stories are told in interaction using several different communicative modalities (language, para-language, gestures, eye movements, bodily positions, material and social artifacts in the immediate context, etc). This makes it important to look at the ways tellers and listeners use all available communicative resources in the narrative situation (Goodwin, 2004).

\section{$\underline{\text { Narrative and communicative disabilities }}$}

A further problem with the literary norms about stories is that social scientific researchers in the field of disability and health research often expect and hope to elicit, find and collect stories that conform to these norms. Most storytellers with what could be called communicative disabilities (persons with, for instance, brain injuries, dementias or other traumas and diseases with consequences for cognitive and linguistic abilities) have problems telling stories that conform to these norms and expectations either in interviews, or in clinical or everyday settings. Doing research with persons with communicative disabilities quite often tends to upset the often implicit and taken-for-granted narrative norms of the researcher.

Researchers who are interested in life histories or the experience of a certain disability and for that reason try to elicit storytelling in the interview situation, often encounter problems conducting interviews with people who have what we call communicative disabilities. In fact, researchers often judge people with communicative disorders to be too hard to interview and therefore many of these individuals have been excluded from research, even though the ambition is to be inclusive (Carlsson et al., 2007).

One consequence of this is that researchers working with this type of material often compile narratives themselves from the interviews in order to create coherent narratives with a beginning, middle and end; that is, a story that adheres to the norms of written text narratives. As a consequence narratives or stories attributed to the interviewees are actually not told by the person with communicative disabilities. They are rather an analytical construction by the researcher joining and ordering fragments from the interview, giving them a temporal order and coherence. 
This procedure has, in fact, profound consequences both for the conception of what a narrative is and for the ways narratives are analyzed - something that is rarely discussed. Due to the fact that interviewees with communicative disabilities often have severe problems telling stories the question emerges of whose story it is that is being told and then presented in research, and of whose voice is heard in the storytelling (cf. Estroff, 1995). Is the story told by the researcher actually the story that the person with disability tried to tell or is it the story that the researcher believes that the interviewee wanted to tell? Another important consequence is that persons with communicative disabilities tend to appear as less competent storytellers than they actually are (cf. Hydén \& Örulv, 2009; Örulv \& Hydén, 2006). Telling stories that don’t comply with the established narrative norms often results in the idea that the teller is defective or incompetent and hence a person whose personhood is questionable (Nelson, 2001, 2002).

An alternative way to think about storytellers with communicative disabilities is to analyze the relationship between story and storytelling event, and the relationship between what could be called the primary storyteller and the vicarious storyteller. We suggest that this way of thinking about stories and storytelling is also applicable to narrative research in general.

\section{$\underline{\text { Various voices }}$}

Telling stories is a relational venture - stories are always part of a joint activity. Several researchers have pointed out that interviews are best understood as being co-constructed (Mishler, 1986). The interviewee's answers to the researcher's question are generally the result of a negotiation concerning the meaning of the interviewer's question. This idea could be used for understanding interviews with persons who struggle with communicative issues, especially in the case of analyzing narratives.

Instead of starting from the assumption that stories in interviews and in other situations are told by one storyteller - in the case of an interview by the interviewee - it could be conceived that stories are thought of as co-constructed by several tellers. Often we are especially interested in one of these storytellers, specifically the interviewee. Hence the interviewee could be considered to be the primary storyteller; it is his or her story that is in focus. The second storyteller, whom we could call the vicarious storyteller, could be the interviewer or some other person. The vicarious storyteller supports the primary storyteller or, in extreme cases, is the one who tells the entire story (cf. Hydén, 2008). That is, the actual telling of the story is accomplished by at least two persons, which makes the storytelling a concerted 
activity and the story something jointly constructed or co-constructed. (The use of the word 'vicarious' in no way implies 'authenticity'; the term is used to name a relation in a coconstructed activity.)

Jointly constructed stories are not only found in interviews with persons with communicative disabilities but also in other types of storytelling situations, such as everyday situations involving family members and friends as well as storytelling in medical and care settings. Joint construction of stories is also something found quite often in storytelling involving participants without communicative disabilities (see Ochs and Capps, 2001 for a review). The problem is rather whether the person with communicative disabilities is able to be both author and what Goffman calls animator of the story - the 'soundbox', the producer of the sounds (Goffman, 1981). If a person has trouble telling a story due to problems with producing speech, as in many cases of aphasia, the vicarious storyteller may act as animator/soundbox but not necessarily as the author of the story. On the other hand, a person with certain types of communicative disabilities may have problems authoring a story, but no problems physically telling a story. Then a vicarious storyteller may act as the author of the story by posing certain questions or prompting certain story lines told by the person with disabilities. As a result, stories in this context are best regarded as joint constructions, where the primary and the vicarious storytellers' contributions vary depending on their relationship. This is something that has implications for the researcher both in terms of how to understand and analyze the story, but also in terms of whose story it is.

In the following we would like to discuss some empirical cases in order to illustrate three different kinds of relationships between a primary and a vicarious storyteller as a way of understanding the various ways in which stories are jointly constructed in this area. These examples are chosen because they highlight the ways the storyteller actively uses the storytelling situation creatively; the ambition is not to introduce a typology. Other examples could of course be suggested, but these three are found quite often in the literature and pose some fundamental analytical problems in the research process.

The first example has to do with situations when the primary storyteller is author of a story but has problems with the actual telling of the story. The vicarious storyteller in this case fulfils the animator function. This is often the case when the primary storyteller suffers from certain forms of aphasia and hence has problems telling a story that he or she has authored. 
The second example is when the primary storyteller is not author of the story but it is the vicarious storyteller that holds this function. This is often the case when the primary storyteller has problems composing a story due to conditions like brain injury. Thirdly, there are cases where the primary storyteller is neither the teller nor the author of a story but is the main principal and figure of the story (for the concepts of 'principal' and 'figure', see Goffman, 1981). This is the case when the primary storyteller is unable to communicate at all.

\section{Animating the story}

When the primary storyteller has problems telling the story in words, the use of other types of communicative resources becomes important. Instances of this are the use of non-verbal resources like gestures or bodily movements or the use of other participants, as well as the use of the interactional organization of the storytelling.

The following example comes from data collected at a Swedish day centre for persons with severe brain damage (Antelius, 2007, 2009a, 2009b; Hydén, 2008). The majority of the centre's participants are between 20 and 60 years of age, and some of them have been in severe car accidents. One of these persons is Margret. She is around 45 years old and has been in contact with the day centre for about five years. One of the nurses working with Margret is Dorothy, who has known Margret for about four years. For an extended period one of the authors of this paper (EA) had conducted fieldwork at the centre, video-recording everyday life (Antelius, 2007, 2009). One afternoon Dorothy asks Margret if she has told Eleonor why she is in a wheelchair.

\section{Example 1}

Dorothy: have you told Eleonor, who is sitting over there ((points towards Eleonor)) why you are in a wheelchair?

\section{Margret: No}

Eleonor: No

I don't think so

Margret: car accidents

Eleonor: accidents? more than one? 
Margret: ((nods)) two

Eleonor: two?

((Margret looks at Dorothy))

Dorothy: you had almost recovered from the first one

Trained yourself

When did it happen?

Margret: one year

Dorothy: one year between the accidents?

Margret: then the second one happened

Dorothy: were you in a car both times?

Margret: Yeah

Dorothy: yes, I thought you rode a motorcycle

Margret: Car

Dorothy: yes it was a car

But you didn't drive yourself?

Margret: yes:s the second time

Dorothy: you drove the second time?

Margret: on my way to $((\mathrm{xxx}))$

Dorothy: on your way to?

Margret: my work

Dorothy: your job yes

Margret: $\quad((\mathrm{xxx}))$ who drove were drunk

Dorothy: he was drunk yes

Margret: $((\mathrm{xxx}))$

Dorothy: did you start your job at night?

((Margret nods))

yes you did work the night shift

Margret: Always

Dorothy suggests that Margret should tell the story about her car accidents. Margret starts doing this using a much-reduced vocabulary. She starts by saying 'car accidents'; the plural form of 'accidents' indicates that she has suffered more than one accident. In response to a question by Eleonor, Margret can specify that she suffered two accidents, but then she apparently cannot elaborate on the answer and turns to Dorothy, who interprets this as a 
request for help. Dorothy helps Margret by putting the events in order; she had almost recovered from the first accident when another car hit her.

Between Dorothy and Margret a sort of joint narration quickly evolves. Either Dorothy puts supportive questions to Margret, who can then fill in more specific information about an event, or Margret uses a short word or phrase (something which is more apparent in Swedish), and Dorothy elaborates on this by posing questions that encourage augmentation. A closer look at the conversation shows that Dorothy is generally familiar with Margret's story. She knows at least the general outline of the events that put Margret into her wheelchair. She also knows the important points in Dorothy's story, for instance that her second accident occurred just when she had recovered from her first accident. She was on her way to her night shift job, was hit by a drunken driver, and bore no responsibility for the accident.

In her supportive utterances Dorothy addresses Margret in the second person, with for instance, 'I thought you rode a motorcycle' and 'You drove the second time?'. These utterances are incorporated into the unfolding narrative and partly substitute for the first person perspective that Dorothy has problems articulating on her own. Dorothy's use of the second-person address form makes it clear that she subordinates her narrative contributions to Margret's story. Dorothy apparently does not want to add any personal story elements outside of what Margret herself wants to tell.

Dorothy's voice enters into a dialogue with Margret's own voice. Dorothy takes hints from Margret in order to help her to reconstruct her experiences using what elsewhere has been called a jigsaw puzzle strategy of communication (Antelius, 2009). Dorothy keeps the narrative close to Margret's own memories, her perspective on the events, and her evaluation of them. In that sense, Dorothy's animative voice basically supports Margret's own authorial voice. In the interaction it is Margret who is the author of the story - not Dorothy.

Being able to pose as the responsible teller in the storytelling event positions Margret as a competent person. She can both execute power over the telling of the story and also, in that way, claim the attention of the audience. In addition, she claims the experiences recounted in the story, being twice involved in severe car accidents. That is, the story told presents the primary storyteller not only as being the person she is in the actual speech situation, but also as a person with experiences and a life history that are quite different from her persona now. 
Margret accomplishes this by organizing the interaction in such a manner that she stands out as the main storyteller.

Furthermore, her telling of the story becomes a move in the interaction that redefines the principals' status and creates a new alignment to the audience (Goffman, 1981). The persons with communicative disabilities are redefining their identities and defending their personhood. They come through as competent storytellers although they don't adhere to the conventional narrative norms.

\section{Enacted and embodied stories}

In some cases the primary storyteller is animator, principal and figure in the story, but not the author, because of problems composing the story (due to something like acquired brain damage). Instead it is the vicarious storyteller who acts as the author of the story.

Mattingly's research on persons with brain trauma $(1994,1998)$ is an illustrative example of this. What Mattingly did was to study clinical practices between occupational therapists and their patients, and she found that the clinical action in itself could be seen as an untold story, i.e. the narrative is lived before it is told. In Mattingly's example (1994: 815ff.) the following takes place. Donna, an occupational therapist, meets Steven, a 20 -year-old who has just regained consciousness after a coma caused by a car accident. He cannot talk, instead he communicates through signalling and writing. It is the first time since the accident that Steven is out of his hospital bed.

Donna starts by asking Steven to comb his hair; when he does not want to, she tells him that it is an exercise that will help improve his balance. With great effort, and with constant compliments from Donna, he then combs his hair. When he indicates that he is done Donna asks him to continue, pointing out places that he has missed. When he is done Steven writes on a piece of paper: 'mirror'. Donna hands him a mirror, adjusts it so that he can see properly and jokingly asks him if he is going to make himself look good for his girlfriend. Steven then writes on the paper again, 'want to go for a ride'.

Donna enthusiastically agrees, 'Great! You want to check out your new place'. 
The tour begins with Donna taking Steven to the main occupational therapy room, telling him that this is where he will be spending a lot of his time because it is here that they will work on strengthening his upper body. As they are about to leave Steven indicates that he is uncomfortable and Donna stops to see what is wrong. Steven indicates pain in his shoulder; Donna then supports his arm and starts moving it. She explains what she is doing, then asks him to do it and says, 'Your left shoulder seems OK but that pain makes you not want to move it. But moving is good. Moving will make it stronger and reduce the spasm'.

When they leave the room, Steven writes 'I want more of a tour before I go back to bed'. Donna says, 'You've got it. This is Universal Hospital'.

As they roll down the corridor, Donna tells him that she is not there on weekends but as he improves and gets stronger, his family will be able to take him out instead. Further down the corridor they pass the nursing station and Donna looks around to see if there are any nurses around who know Steven. Steven then writes 'Is Beth here?'. Beth comes out and they have a quick, warm conversation where Beth tells him she is glad he is up. Steven writes 'please visit' on a note to Beth. Donna and Steven then proceed with their tour for a few more minutes before Donna asks him if he is tired. Steven does a thumbs-up and they return to his room. The session ends there.

One of Mattingly's main arguments is that this is a story told through social doings rather than through words. Even though Donna responds verbally to Steven it is primarily her and Steven's actions that constitute the story. Mattingly argues that this story consists of 'emplotted time', that is, a time of social doings that are created by actions (by the individual and others) rather than by words. What Donna, the therapist, manages to do is to 'emplot' Steven into a story, a story that plays upon the theme of Steven's re-entry into the everyday, public world $(1994,816)$. This episode starts with Donna turning the hair-combing situation from a balance activity into a self-care activity (by pointing out places he has missed and jokingly asking him if he is making himself look good for his girlfriend. Steven accepts this meaning as he asks for a mirror to check himself out, something one might do after combing one's hair, not after finishing a balance exercise).

Steven then initiates the next phase of the session by requesting to go for a ride in the hospital, something Donna agrees to, and this turn into the plot of the re-entry story by saying 
that he wants to check out his new place. The ride, which could have meant just going up and down the hall, is instead turned into a meaningful event in the re-entry story when Donna suggests that it is a way for Steven to check out his new place, a chance to see and be seen. This story is connected to another story (that he has to work hard in order to get stronger and eventually re-enter the everyday world) and is created through the enactment and embodiment of both Donna and Steven rather than by them telling the story in words.

As we see Donna acts as the author of this story. She is the one initiating the re-entry story. However, we see that Steven is the figure of the story and he is also both teller/actor and the principal of the story. Through his action of asking for the mirror, he accepts Donna's attempt at telling a re-entry story and becomes the principal teller of the story (even though he is not the author of it) by wanting to go for the ride, wanting to say 'hi' to Beth, etc. Donna supports him in telling this story, i.e. she acts as Steven's vicarious storyteller. Steven is also taking responsibility for the telling of the story, making himself the principal of it. Steven is in fact also animator of the story even though he does not utter any sounds (in fact he cannot speak at all). However, and this is Mattingly's main point, one can tell a story without uttering words, one can tell the story through one's social doings. Hence, Steven's actions could be regarded as him being the animator of an embodied/enacted story.

\section{The mute storyteller}

The most extreme case of communicative disablement is of course if a person is not able to talk at all or communicate in any other way. But this doesn't mean that stories are irrelevant or that a person in some sense may not have at least a potential story to tell.

The American philosopher Hilde Nelson writes about her sister Carla who was born in the early 1950s with hydrocephaly, something that not much could be done about at that time. As a consequence of this neural tube disorder Carla couldn't lift her head, grasp objects, or speak. Carla lived only 18 months; she was never able to express her own point of view, and even less able to tell about herself. As a result her family engaged in what Hilde Nelson describes as 'the practice of holding the individual in personhood by constructing or maintaining a personal identity for her when she cannot, or can no longer, do it for herself.' (Nelson 2002: 30) 
When the family told about Carla or told stories that in some way included Carla, she became a part of the family. She became part of a closely-knit web of stories that presented her as an agent or active subject. That is, as a child that preferred or liked certain things more than others, who had intentions and a will. Carla was treated as a person, with all the respect that is associated with having a personhood in our culture. Being a person means that other persons have certain moral obligations towards you; you have to treat a person in certain ways, in contrast to your treatment of non-living things - something that is quite important if the person is not able to express his/her own point of view. Carla then in a way became the principal of stories she neither animated nor authored, although she was the main figure.

As readers of Nelson's article we never get any examples of the stories that the family members told about Carla. We can however find some similar examples in the research that David Goode reported on in his book A World Without Words (1995). In this book he discusses two girls, neither of whom could use formal language. Their families, however, are convinced that they can communicate with them in other ways. One of the things that the family members do is to create small stories about what the girls want. One of the girls is named Bianca. At one point during his fieldwork in the family Bianca became upset and started making sounds. Bianca's mother, Barbara, turned to David Goode, the researcher ‘...and offered an explanation, "She wants her milk." I asked her how she knew this, and she said that Bianca usually would have gotten her milk by now, but she (Barbara) had forgotten tonight.' (Goode 1994:71)

This example is interesting because it illustrates how family members orient themselves towards the first-person perspective of Bianca. They try to understand what she wants from her perspective. So even though Bianca's mother referred to her in the third person, she is invoking a first-person perspective; Bianca is treated as an agent although she cannot communicate by language nor tell stories herself or about herself and her experiences.

The same appears to have happened in Carla's family. The individual family members tried to invoke Carla's first-person perspective in at least some of the stories told about her. By being the node of the family's narratives about her, Carla also received an identity - she became someone specific. Hilde Nelson writes that the more stories about Carla the other five family members told, 'the richer her [Carla's] identity became'. A central point that Hilde Nelson makes is that it is through telling stories about Carla her family members acknowledged her 
as a person, that is, treating Carla as if she is a person worthy of full respect. In order to be able to do this you have to acknowledge the possibility of Carla voicing a first-person perspective on herself, her family and the world. Hence, in order to respect her as a person her narrative identity has to include a first-person perspective.

This was despite that fact that the stories the family members told about Carla were all told entirely from the third-person perspective and also in the form of third person, that is, stories about another person where the teller is not identical to the main character of the story.

One problem with the idea of family members narrating Carla's identity is that they are telling stories about Carla that they don't know if she would accept or recognize as being true if she had had the capability to give voice to her own perspective. That is, Carla is positioned or narrated into an identity by others rather than positioning herself.

The story told by Nelson is especially compelling because Carla was not able to present her own point of view. But situations where others narratively position persons are quite common, as Nelson has discussed elsewhere (Nelson, 2001). It is a common experience for most of us that other people tell stories about us and as a consequence position us as persons, assigning us an identity. If we don't accept the positioning or the story, one possibility is of course to object to the story and try to revise it or complement it. If that doesn't work we have the further possibility of constructing and telling another story that we feel conveys our experiences and our perspective on events in a more accurate way. This new story told in critical dialogue with the first one is what Hilde Nelson calls a counter story (Nelson 2001). Contesting stories about oneself told by others, and maybe also telling counter stories is a common experience in most families and in many other contexts. (For a general discussion about this the discussion in Couser, 2004. For a more specific discussion about telling stories 'for' others in relation to communicative disabilities, see Antelius 2009a, 2009c.)

Having the right to tell autobiographical stories is a way to sustain a sense of self and define one's identity. Generally these are stories told from a first-person perspective, that is, telling something about one's own experiences and history in order to tell about a defining moment about how someone came to be the person he or she claims they are. Carla was unable to do this; she could not tell any story on her own. Instead she became a person through stories others told about her; her personhood and identity came to life and existed through this 
storytelling activity. Using and expanding Goffman's terminology it could be argued that Carla became the attributed principal of the family's stories.

\section{Discussion and Conclusions}

We have tried to point out that a problem exists here. Much of the research on stories, disability and illness is focused on the verbal embodiment of stories, while the other kinds of embodiment have been left out. Strangely enough it's the body and especially the diseased body that often has been forgotten. The body may become a theme of the story but bodies and their interaction are often left out of the story, the analysis and the process of understanding of the story. It's obvious that diseases and traumas affect the storytelling body, something that will have many consequences for the person's ability to tell and understand stories.

Leaving the embodiment or the actual telling of the story out of the picture means that nonverbal communicative resources - gestures, eye movements, the use of other persons (and bodies) as vicarious voices, and so on - will also be left out. These resources are generally important both to ill persons telling stories and to an understanding of the organization of illness narratives.

We suggest that the telling of and listening to stories should be regarded as an embodied activity that engages both body and mind, and furthermore that stories are anchored in the storyteller's and the listeners' bodies (see Gerrig, 1993). Without this anchoring a story could not be told, consumed, constructed nor interpreted. Embodiment may mean several different things in this context. The three aspects of embodiment have become especially relevant through the discussion and analysis of the examples.

First of all, narratives are produced through a speech event, making a story part of, or embodied in, a network of social relations. The speech event can be thought of in terms of the relations between the participants and the functional roles these take on. In other words the creation of narrative meaning or meaning in narrative is something that takes place inside this network of social relations. Meaning is created as the teller designs his or her story to be heard by a certain participant; the listener, on the other hand, listens to a story as though it has been designed for him or her. In both telling and listening to stories participants make use of what they see as their shared background knowledge experiences. It's through this process that meaning is constructed. That is, the narrative text gets its life through the storytelling 
even. For this reason it's important to take social and cultural contextual aspects into account in the analysis of narratives.

This is something that is relevant in relation to the study of narrative in research areas like disability, health and illness, since meaning often is established through the active use and engagement of all participants in the storytelling event. Research interviewers as well as family members and others become involved in discussing, revising and re-organizing stories told.

A second aspect of embodied storytelling has to do with fact that telling and listening to stories is an activity that is accomplished through the use of bodies. Both speaking and listening are basically bodily processes. The body and its parts are also used as communicative instruments; gestures, eye movements, voice, etc. are bodily, physical resources that are used in the telling of a story in order to mimic, to dramatize or to direct the attention of the listeners. Although this may seem self-evident, the use of bodily resources is something that becomes quite important in the study of illness narratives and ill persons telling stories. The reason for this is that some persons cannot use their bodies due to medical problems. Persons with brain traumas or Alzheimer's disease or other cognitive impairments have problems using one specific part of the body - the brain - while other persons have problems speaking due to diseases. In all these cases the teller needs to use other communicative resources than verbal. They need to use non-verbal resources like gestures and eye movements, as well as the social organization of the storytelling event by engaging what could be called vicarious voices in order to tell a story. That is, another person may have to step in and help to organize and tell the story, acting as a vicarious voice.

Finally, narrative embodiment also implies the bodily involvement of both teller and listener in terms of their sympathetic emotional engagement in the story. Listening to a story is not about registering the speech sounds in order to be able to construct a temporal sequence of events and a plot. Rather it is about being fully involved - mind and body - in the events that transpire in the storyworld. German-American literary theorist Wolfgang Iser wrote about the reader of books that 'the constitution of meaning (...) gains its full significance when something happens to the reader' (Iser, 1978:. 152). It's in the moment when the listener surrenders to the events in the story and reacts through bodily involvement that the full meaning in the story comes to the forefront. 
This is an aspect that is especially important in tellings about illness, trauma and disease. Illness stories often are about interrupted lives, changes in the future life and redefinitions of identity - that is, profound existential changes. This implies that special demands are put on the generosity of the listener. It's only through the act of patient and tireless listening that the relationship between the teller and his or her ill body will emerge through the body versions presented in the storyworld. It's through the process of embodied storytelling and listening to them that it becomes possible to realize that at least some stories are told by bodies that differ from the norms.

In order to be able to study stories told by persons living with severe communication disorders not only the concept of narrative has to be re-defined, but also the methods used. It seems that Kovarsky's and Crago's (1991) call for an ethnography of communication disorders is very apt. They want to extend Dell Hymes' original focus on 'the ethnography of speaking' (Hymes, 1964) to the area of disability studies. Dell Hymes (1964) argued that it is necessary to study communication in its wider context in order to be able to explore the relationship between language and social life, and that language should be regarded as an interactional resource. He also argued that ethnographic methods ought to be used in order to study this. Kovarsky and Crago (1991) argued along the same lines, writing that researchers need to observe both what people actually say and cannot say, in various contexts. This is the only way, they argue, in which it becomes possible to fully account for the complex relations between language, culture and communicative disability. (About the relevance of ethnography in narrative studies see the discussion in Riessman, 2008, as well as the concept of 'narrative ethnography' in Gubrium and Holstein, 2008.)

What they argue is that when studying communication, and thus also communication disorders, language, or the loss of language, cannot be separated from the people who speak or do not speak. Hence, such studies must take place in context, using ethnographic methods (such as participant observations). We thus suggest that in a field such as communicative disability, narrative methods are perhaps best used if combined with ethnographic methods. Research interviews can tell us a great deal about what it means to live with disabilities but perhaps they cannot tell us everything, especially if we do not see that we must redefine what a narrative could be, and how it can be told. 


\section{$\underline{\text { References }}$}

Antelius, E. (2007). The meaning of the present: Hope and foreclosure in narrations about people with severe brain damage. Medical Anthropology Quarterly, 21, 324-342.

Antelius, E. (2009). Whose body is it anyway? Verbalization, embodiment, and the creation of narratives. Health $13,357-375$. (a)

Antelius, E. (2009). 'Would you like to use one of these or would you rather be able to talk?' facilitated and/or augmentative communication and the preference for speaking. Scandinavian Journal of Disability Research, 11, 257-274. (b)

Antelius, E. (2009). Different Voices, Different Stories. Communication, identity and meaning among peole with acquired brain damage. (Diss.) Linköping: Linköping Studies in Arts and Science, Linköping university. (c)

Bauman, R. (1987). Story, performance, and event. Contextual studies of oral narrative. Cambridge: Cambridge University Press.

Bauman, R., \& Briggs, C. L. (1990). Poetics and performance as critical perspectives on language and social life. Annual Review of Anthropology, 19, 59-88.

Carlsson, E., Paterson, B. L., Scott-Findlay, S., Ehnfors, M. \& Ehrenberg, A. (2007). Methodological issues in interviews involving people with communication impairments after acquired brain damage. Qualitative Health Research 2 17, 1361-1371.

Couser, G. T. (2004). Vulnerable Subjects. Ethics and Life Writing. Ithaca: Cornell University Press.

Estroff, S. E. (1995). Whose story is it anyway? Authority, voice and responsibility in narratives of chronic illness. In S. K. Toombs, D. Barnard \& R. A. Carson (Eds.), Chronic illness. From experience to policy, 77-102. Bloomington, Indiana: Indiana University Press.

Gerrig, R. J. (1993). Experiencing Narrative Worlds. On the Psychological Activities of Reading. New Haven: Yale University Press. 
Goffman, E. (1981). Forms of talk. Pennsylvania: University of Pennsylvania Press.

Goode, D. (1995). A world without words. The social construction of children born deaf and blind. Philadelphia: Temple University Press.

Goodley, D. \& Tragaskis, C. (2006). Storying disability and impairment: Retrospective accounts of disabled family life. Qualitative Health Research, 16, 630-646.

Goodwin, C. (2004). A competent speaker who can’t speak: The social life of aphasia. Journal of Linguistic Anthropology, 14, 151-170.

Gubrium, J. F. \& Holstein, J.A. (2008). Narrative Ethnography. In S. Hesse-Biber \& P. Leavy (Eds.), Handbook of Emergent Methods, 241-264. New York: Guilford Publications.

Heath, S. B. (1983). Ways with Words. Language, Life, and Work in Communities and Classrooms. New York: Cambridge University Press.

Hydén, L. C. (2008). Broken and vicarious voices in narratives. In L. C. Hydén \& J. Brockmeier (Eds.), Health, culture and illness: Broken narratives. New York: Routledge.

Hydén, L. C., \& Brockmeier, J. (2008). Introduction: The field of illness narratives. In L. C. Hydén \& J. Brockmeier (Eds.), Health, culture and illness: Broken narratives, 1-15. New York: Routledge.

Hydén, L. C., \& Örulv, L. (2009). Narrative and identity in Alzheimer's disease: A case study. Journal of Aging Studies, 23, 205-214.

Hymes, D. H. (1964). Towards ethnographies of communication: The analysis of communicative events. American Anthropologist, 66, 1-34.

Iser, W. (1978). The act of reading. A theory of aesthetic response. Baltimore: Johns Hopkins University Press. 
Kovarsky, D. \& Crago, M. (1991). Towards the ethnography of communication disorders. National Student Speech Language Hearing Association Journal 2 18, 44-55.

Langellier, K. (2001). 'You're marked': Breast cancer, tattoo, and the narrative performance of identity. In J. Brockmeier \& D. Carbaugh (Eds.), Narrative and identity: Studies in autobiography, self and culture, 145-184). Amsterdam: John Benjamins.

Langellier, K. M., \& Peterson, E. E. (2004). Storytelling in daily life: Performing narrative. Philadelphia: Temple University Press.

Linell, P. (2005). The written language bias in linguistics. London: Routledge.

Mattingly, C. (1994). The concept of therapeutic 'emplotment'. Social Science and Medicine, $38,811-822$.

Mattingly, C. (1998). Healing dramas and clinical plots. The narrative structure of experience. New York: Cambridge University Press.

Mishler, E. G. (1986). Research interviewing. Context and narrative. Cambridge: Harvard University Press.

Nelson, H. L. (2001). Damaged identities, narrative repair. Ithaca: Cornell University Press.

Nelson, H. L. (2002). What child is this? Hastings Center Report 32, 29-38.

Ochs, E. \& Capps, L. (2001). Living narrative. Creating lives in everyday storytelling. Cambridge: Harvard University Press.

Örulv, L. \& Hydén, L.C. (2006). Confabulation: Sense-making, self-making and worldmaking in dementia. Discourse Studies, 8, 647-673.

Peterson, E. E., \& Langellier, K. M. (2006). The performance turn in narrative studies. Narrative Inquiry, 16, 173-180. 
Riessman, C. K. (2008). Narrative Methods for the Human Sciences. London: Sage.

Smith, B. (2007). The state of the art in narrative inqury: Some reflections. Narrative Inquiry, 17, 391-398.

Smith, B., \& Sparkes, A. C. (2008). Narrative and its potential contribution to disability studies. Disability \& Society, 23, 17-28.

Walsh, R. (2007). The rhetoric of fictionality. Columbus: The Ohio State University Press. 